\title{
Effects of converting natural grasslands into planted grasslands on ecosystem respiration: a case study in Inner Mongolia, China
}

\author{
ZHANG Meng, LI Xiaobing*", WANG Hong, DENG Fei, LI Xu, MI Xue
}

State Key Laboratory of Earth Surface Processes and Resource Ecology, College of Resources Science and Technology, Beijing Normal University, Beijing 100875, China

\begin{abstract}
With increasingly intensifying degradation of natural grasslands and rapidly increasing demand of high quality forages, natural grasslands in China have been converted into planted grasslands at an unprecedented rate and the magnitude of the conversion in Inner Mongolia is among the national highest where the areal extent of planted grasslands ranks the second in China. Such land-use changes (i.e., converting natural grasslands into planted grasslands) can significantly affect carbon stocks and carbon emissions in grassland ecosystems. In this study, we analyzed the effects of converting natural grasslands into planted grasslands (including Medicago sativa, Elymus cylindricus, and M. sativa+E. cylindricus) on ecosystem respiration $\left(F_{\text {eco }}\right)$ in Inner Mongolia of China. Diurnal $F_{\text {eco }}$ and its components (i.e., total soil respiration $\left(F_{\mathrm{ts}}\right)$, soil heterotrophic respiration $\left(F_{\mathrm{sh}}\right)$ and vegetation autotrophic respiration $\left.\left(F_{\mathrm{va}}\right)\right)$ were measured in 2012 (27 July to 5 August) and 2013 (18 July to 25 July) in the natural and planted grasslands. Meteorological data, aboveground vegetation data and soil data were simultaneously collected to analyze the relationships between respiration fluxes and environmental factors in those grasslands. In 2012, the daily mean $F_{\text {eco }}$ in the $M$. sativa grassland was higher than that in the natural grassland, and the daily mean $F_{\mathrm{va}}$ was higher in all planted grasslands (i.e., M. sativa, E. cylindricus, and M. sativa + E. cylindricus) than in the natural grassland. In contrast, the daily mean $F_{\mathrm{ts}}$ and $F_{\mathrm{sh}}$ were lower in all planted grasslands than in the natural grassland. In 2013, the daily mean $F_{\mathrm{eco}}, F_{\mathrm{ts}}$ and $F_{\mathrm{va}}$ in all planted grasslands were higher than those in the natural grassland, and the daily mean $F_{\mathrm{sh}}$ in the $M$. sativa + E. cylindricus grassland was higher than that in the natural grassland. The two-year experimental results suggested that the conversion of natural grasslands into planted grasslands can generally increase the $F_{\text {eco }}$ and the increase in $F_{\text {eco }}$ is more pronounced when the plantation becomes more mature. The results also indicated that $F_{\text {sh }}$ contributed more to $F_{\text {eco }}$ in the natural grassland whereas $F_{\mathrm{va}}$ contributed more to $F_{\text {eco }}$ in the planted grasslands. The regression analyses show that climate factors (air temperature and relative humidity) and soil properties (soil organic matter, soil temperature, and soil moisture) strongly affected respiration fluxes in all grasslands. However, our observation period was admittedly too short. To fully understand the effects of such land-use changes (i.e., converting natural grasslands into planted grasslands) on respiration fluxes, longer-term observations are badly needed.
\end{abstract}

Keywords: natural grasslands; planted grasslands; ecosystem respiration; soil respiration; vegetation autotrophic respiration; Inner Mongolia

Citation: ZHANG Meng, LI Xiaobing, WANG Hong, DENG Fei, LI Xu, MI Xue. 2017. Effects of converting natural grasslands into planted grasslands on ecosystem respiration: a case study in Inner Mongolia, China. Journal of Arid Land, 9(1): 38-50. doi: 10.1007/s40333-016-0059-y

*Corresponding author: LI Xiaobing (E-mail: xbli@bnu.edu.cn)

Received 2015-12-23; revised 2016-06-17; accepted 2016-07-15

(C) Xinjiang Institute of Ecology and Geography, Chinese Academy of Sciences, Science Press and Springer-Verlag Berlin Heidelberg 2017 


\section{Introduction}

Human-induced global climate change has become a major concern around the world and human injection of carbon dioxide $\left(\mathrm{CO}_{2}\right)$ into the atmosphere shares a disproportionally large responsibility for the observed global change (Dai et al., 2016). Consequently, carbon sequestration measures have been intensively sought for mitigating the $\mathrm{CO}_{2}$-rising issue. Subsequently, carbon cycling in terrestrial ecosystems has become a hotspot worldwide because of the challenges of global climate change (Zhan et al., 2012). Grasslands, covering about $30 \%$ of the global land surface and storing $28 \%$ to $37 \%$ of carbon in terrestrial ecosystems, have been examined to explore the potentials for carbon sequestration (Lal, 2004; IPCC, 2007). As a gigantic carbon pool, grassland ecosystem plays a critical role in the global carbon cycling (Monkany et al., 2006). In China, the natural grassland ecosystem is the largest terrestrial ecosystem, covering about $41 \%$ of the total land area ( $\mathrm{Li}$ et al., 2015; Zhang et al., 2016). Nevertheless, with increasingly intensifying degradation of natural grasslands and rapidly increasing demand of high quality forages, natural grasslands in China have been converted into planted grasslands at an unprecedented rate, and the magnitude of the conversion in Inner Mongolia is among the national highest where the areal extent of planted grasslands ranks the second in China (Zhang et al., 2012; Deng et al., 2014). However, such land-use changes (i.e., converting natural grasslands into planted grasslands) may effectively alter the exchange of carbon between the atmosphere and the ecosystems (IPCC, 2007) through altering the ecosystem respiration $\left(F_{\text {eco }}\right)$ and it components (Zhang et al., 2012).

$F_{\text {eco }}$ comprises the aboveground plant respiration and soil respiration (including soil heterotrophic (microbial respiration and soil organic matter decomposition) respiration and soil autotrophic (root) respiration). $F_{\text {eco }}$ can tilt the balance in the global carbon cycling through sequestrating $\mathrm{CO}_{2}$ from the atmosphere or releasing $\mathrm{CO}_{2}$ to the atmosphere and can play an important role in mitigating or accelerating climate change. There are many studies on the effects of land-use changes on $F_{\text {eco }}$ and its components. For example, some studies reported that land-use changes can strongly influence the carbon allocation pattern of ecosystems through altering the vegetation structure and species composition (e.g., Varella et al., 2004; Yang et al., 2004; Wang et al., 2006; Qi et al., 2007; Xie et al., 2010; Rong et al., 2015; Xie and Wu, 2016). Other studies suggested that land-use changes can strongly affect soil respiration through influencing the litter input into the soil and the carbon substrates supplied to the microbes (e.g., Bremer et al., 1998; Pendall et al., 2010; Han et al., 2012; Gong et al., 2014). But, the effects of converting natural grasslands into planted grasslands on $F_{\text {eco }}$ and its components remain poorly understood (Aslam et al., 2000; Zhang et al., 2012).

$F_{\text {eco }}$ and its components were widely reported to be directly related with such environmental factors as soil properties, vegetation types, and climate parameters (Wang et al., 2003; Frank et al., 2006; Holst et al., 2008; Gomez-Casanovas et al., 2012; Peri et al., 2015). More specifically, it was reported that soil moisture and soil temperature could explain more than half of the variations in soil respiration (Flanagan and Johnson, 2005; Wu et al., 2010; Rong et al., 2015). And, air temperature (Valentini et al., 2000; Reichstein et al., 2005; Chen et al., 2014) and relative humidity (Zhang et al., 2012; Borchard et al., 2015; Brito et al., 2015) have also been proven to affect the $F_{\text {eco }}$ and its components. The approaches used to examine the relationships between $F_{\text {eco }}$ (and its components) and environmental factors include linear model (Rochette et al., 1991; Davidson et al., 1998), quadratic model (Holthausen and Caldwell, 1980; Mielnick and Dugas, 2000), logistic model (Schlentner and Van Cleve, 1985; Jenkinson, 1990), hyperbolic model (Liu et al., 2002), exponential model (Grace and Rayment, 2000; Lu et al., 2013) and Arrhenius equation (Thierron and Laudelout, 1996; Fang and Moncrieff, 2001).

Our objective was to assess the variations of $F_{\text {eco }}$ and its components after the conversion of natural grasslands into planted grasslands, and also to analyze the relationships between respiration fluxes (i.e., ecosystem respiration, $F_{\text {eco }}$; total soil respiration, $F_{\mathrm{ts}}$; soil heterotrophic respiration, $F_{\text {sh }}$; and vegetation autotrophic respiration, $F_{\text {va }}$ ) and environmental factors (i.e., soil properties, vegetation and climate factors) in the natural and planted grasslands. 


\section{Materials and methods}

\subsection{Study area}

The study area is situated in Duolun County $\left(41^{\circ} 46^{\prime}-42^{\circ} 39^{\prime} \mathrm{N}, 115^{\circ} 51^{\prime}-116^{\circ} 54^{\prime} \mathrm{E}\right.$; 1150 to $1800 \mathrm{~m}$ a.s.1.), Inner Mongolia Autonomous Region of China. The area is characterized by a semi-arid continental climate with the mean annual precipitation of $385.5 \mathrm{~mm}$ and the annual mean temperature of $1.6^{\circ} \mathrm{C}$. It should be noted that about $2 / 3$ of annual total precipitation occurred in the rainy season from June to August. The monthly mean temperature ranged from $-21.4^{\circ} \mathrm{C}$ (the minimum) in December to $17.8^{\circ} \mathrm{C}$ (the maximum) in July during the study period from June 2012 to September 2013 (Fig. 1). The mean annual frost-free period is approximately $100 \mathrm{~d}$, the mean annual sunshine hour is about $3109.9 \mathrm{~h}$, and the mean annual pan evaporation is $1748 \mathrm{~mm}$.

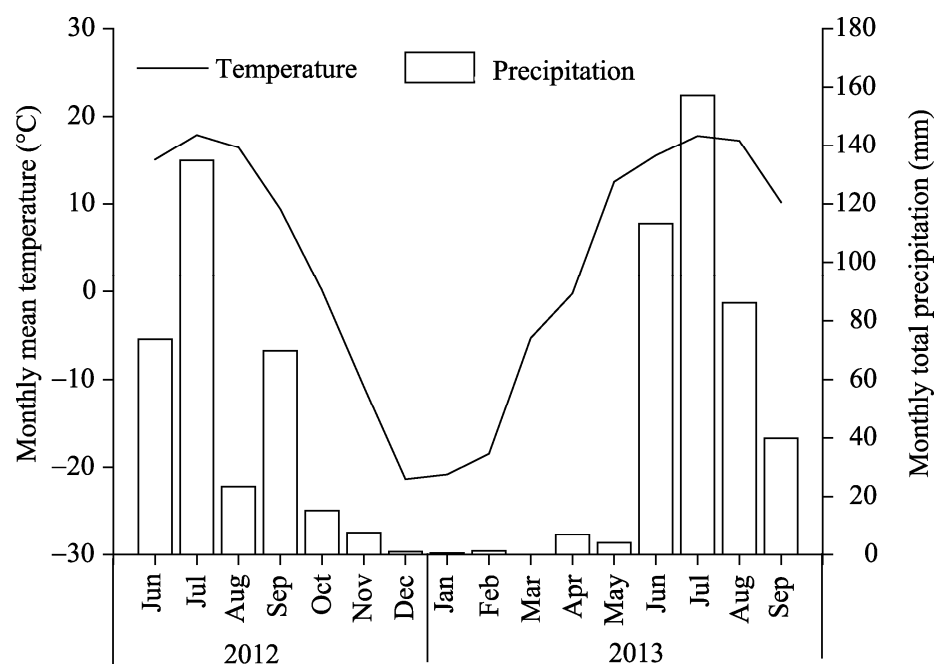

Fig. 1 Monthly mean temperature and monthly total precipitation from June of 2012 to September of 2013

\subsection{Experimental design}

The experiments were conducted under four different grassland types: one type of natural grassland (NG) and three types of planted grasslands (PG). The three types of planted grasslands were converted from a well-protected natural grassland in 2012. The selected natural grassland was several hundred meters away from the planted grasslands and was dominated by Carex tristachya, Leymus chinensis, and Artemisia frigida. Because Medicago sativa and Elymus cylindricus are the major sources of artificial forage in the study area, the three types of planted grasslands were sown with $M$. sativa $\left(22.5 \mathrm{~kg}\right.$ seeds $\left./ \mathrm{hm}^{2}\right)$, E. cylindricus $\left(22.5 \mathrm{~kg}\right.$ seeds $\left./ \mathrm{hm}^{2}\right)$, and M. sativa + E. cylindricus (18.9 and $8.1 \mathrm{~kg}$ seeds $/ \mathrm{hm}^{2}$ ), respectively. Before sowing on 30 May of 2012, the planted grassland sites were mowed to ground level and tilled to a soil depth of 25-30 $\mathrm{cm}$ using a rototiller to eliminate the natural vegetation. The seeds were sown in rows with a space of $18-20 \mathrm{~cm}$ between adjacent rows. Thereafter, no irrigation or fertilizer was applied. All the natural and planted grasslands were cut for hay in late August. The experimental plots were about $5 \mathrm{~m} \times 3 \mathrm{~m}$ in size and each of the four types had three replicated plots (i.e., a total of 12 plots).

\subsection{Data acquisition}

We observed the respiration fluxes on clear days during the fast-growth stages of vegetation, i.e., from 27 July to 5 August of 2012 and from 18 July to 25 July of 2013, using an Automated Soil $\mathrm{CO}_{2}$ Flux System (Li-8150, LI-COR Inc., Lincoln, Nebraska, USA) in combination with an infrared gas analyzer. For each plot, 6 PVC collars with a basal area of $317.8 \mathrm{~cm}^{2}$ each were evenly inserted into the $10 \mathrm{~cm}$ soil depth 1 day before the measurements to allow the soil to recover from the installation-resulted disturbance. Each PVC collar contained a soil chamber 
(LI-8100-104, LI-COR Inc., Lincoln, Nebraska, USA). The chamber was opaque to prevent plants from conducting photosynthesis during the carbon flux measurements. Four types of respiration fluxes were analyzed in this study, i.e., ecosystem respiration $\left(F_{\text {eco }}\right)$, total soil respiration $\left(F_{\text {ts }}\right)$, soil heterotrophic respiration $\left(F_{\mathrm{sh}}\right)$, and vegetation autotrophic respiration ( $F_{\text {va }}$ including aboveground plant respiration and root respiration). The former three types (i.e., $F_{\text {eco }}, F_{\mathrm{ts}}$, and $F_{\mathrm{sh}}$ ) could be directly measured using the measurement equipment under three scenarios. In the first scenario, aboveground plants and soils (including the roots) were included to measure the $F_{\text {eco. }}$ In the second scenario, all aboveground plants were cut off from the ground and put outside the chamber to measure the $F_{\text {ts. }}$. In the third scenario, the $F_{\text {sh }}$ was measured on the bare soil where there was almost no roots distributed. Finally, the $F_{\text {va }}$ was obtained by subtracting $F_{\text {sh }}$ from $F_{\text {eco }}$ (i.e., $F_{\text {va }}=F_{\text {eco }}-F_{\text {sh }}$ ). The measurements were made during daytime from 06:00 to 20:00 with 30-min measuring intervals.

Air temperature, relative humidity, soil temperature $(0-10 \mathrm{~cm})$ and soil moisture $(0-10 \mathrm{~cm})$ were measured during the experimental period (from May of 2012 to September of 2013) using a Dynamet automatic weather station (Dynamax, Houston, Texas, USA) and an EM50 datalogger (Decagon Devices, Pullman, Washington, USA).

During the experimental period, three $1 \mathrm{~m} \times 1 \mathrm{~m}$ quadrats were randomly established in each plot and all the aboveground plants were clipped. All plant samples were oven-dried at $80^{\circ} \mathrm{C}$ to constant weight to estimate the aboveground biomass. In each plot, soil bulk density was directly measured using cutting ring method and three replicates of soil samples were collected at the depth of $0-10 \mathrm{~cm}$ for laboratory analysis. Those soil samples were air-dried and sieved through a 2-mm sieve and the soil organic carbon (SOC) was measured using the Walkey-Black adaptation of volumetric method (Walkley and Black, 1934).

\subsection{Data analysis}

Regression analyses were conducted to determine the relationships between respiration fluxes and environmental factors using linear, quadratic, cubic, logistic, exponential and hyperbolic methods. These analyses were performed with SPSS 13.0 statistical software (IBM Inc., Chicago, IL, USA) and then the optimal regression equations (i.e., those with the greatest $R^{2}$ value, the least residual, and the higher confidence level $(P<0.01$ or $P<0.05))$ were chosen for use in the subsequent calculations. Equations 1 and 2 were used to modify the initial observed carbon fluxes to ensure the comparability between different measurements in terms of the environmental conditions among different grassland types. The results were plotted using Origin 7.5 software.

$$
\begin{gathered}
F_{i}=f\left(i_{\text {mean }}\right) . \\
\hat{F}=\sum a_{i} F_{i} / N .
\end{gathered}
$$

Where, $F_{i}$ is the carbon flux modified by environmental factor $i$ (i.e., soil temperature or soil moisture for $F_{\mathrm{sh}}$ and $F_{\mathrm{ts}}$, and air temperature or relative humidity for $F_{\mathrm{eco}}$ ) after regression analyses; $f$ is the best-fit regression equation; $i_{\text {mean }}$ is the hourly mean value of environmental factor $i$ during the observation period in all sampling plots; $\hat{F}$ is the modified carbon flux with account of the time of the measurements; $\alpha_{i}$ is the weight of $F_{i}$ for $\hat{F}$, and it was assigned as 1 in this study; and $N$ is the number of environmental factors $(N=2)$.

We used one-way analysis of variance (ANOVA) to test the differences in respiration fluxes among the four grassland types. The difference was considered significant at the $P<0.05$ level.

\section{Results}

\subsection{Ecosystem respiration $\left(F_{\text {eco }}\right)$ and vegetation autotrophic respiration $\left(F_{\text {va }}\right)$}

Figure 2 shows the diurnal variations of $F_{\text {eco }}$ and its components after modification during the experimental period. In 2012 (27 July to 5 August), the hourly $F_{\text {eco }}$ was higher in the MS (Medicago sativa grassland) than that in the NG (natural grassland) in the morning, and the opposite was true in the afternoon (Fig. 2a). EC (Elymus cylindricus grassland) and ME (M. 
2012
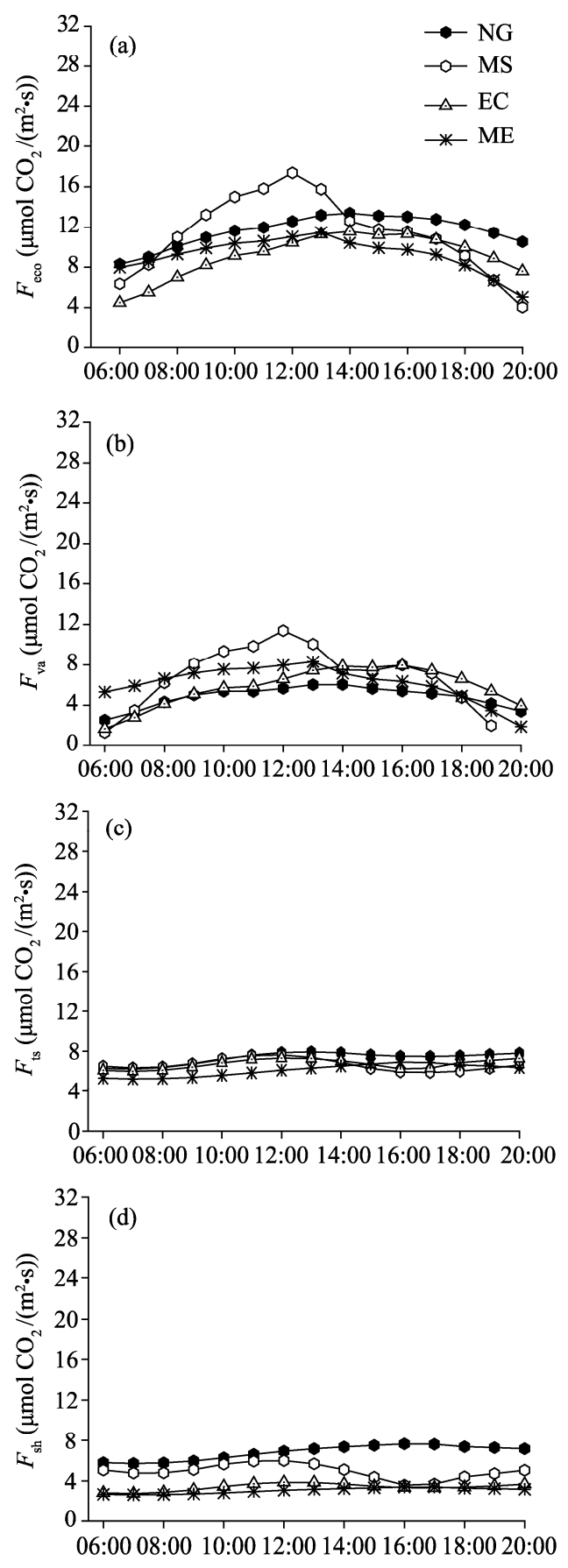

Time
2013
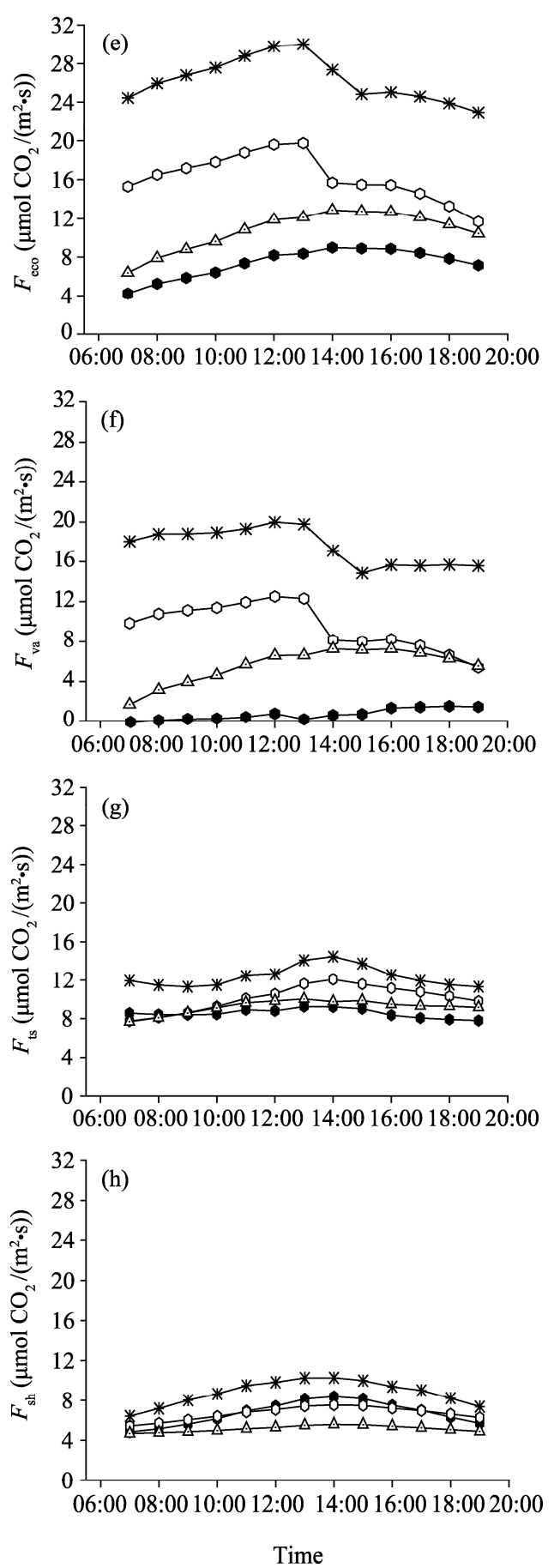

Fig. 2 Variations of respiration fluxes (after modification) during daytime (06:00-20:00) of observation periods (27 July to 5 August of 2012 and 18 July to 25 July of 2013) under four grassland types. $F_{\text {eco, }}$ ecosystem respiration; $F_{\mathrm{va}}$, vegetation autotrophic respiration; $F_{\mathrm{ts}}$, total soil respiration; $F_{\mathrm{sh}}$, soil heterotrophic respiration. NG, natural grassland; MS, Medicago sativa grassland; EC, Elymus cylindricus grassland; ME, M. sativa $+E$. cylindricus grassland.

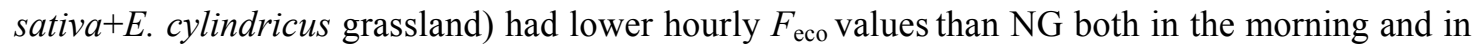
the afternoon. On the average, the daily mean $F_{\text {eco }}$ in the MS was higher than that in the NG 
(Table 1). The hourly $F_{\text {va }}$ values in the PG (three types of planted grasslands, including MS, EC, and $\mathrm{ME}$ ) were higher than that in the NG during most of the observation period (Fig. 2b). Consequently, daily $F_{\text {va }}$ values in the PG (MS, EC, and ME) were also higher than that in the NG with the MS having the highest daily $F_{\text {va }}$ (Table 1 ).

In 2013 (18 July to 25 July), both the hourly and daily mean $F_{\text {eco }}$ were lowest in the NG and highest in the ME (Fig. 2e; Table 1). The daily $F_{\text {eco }}$ in the MS was 2 times higher than that in the NG and the daily $F_{\text {eco }}$ in the ME was 3 times higher than that in the NG (Table 1). Similarly, both the hourly and daily mean $F_{\text {va }}$ values were lowest in the NG and highest in the ME (Fig. 2f; Table 1). In comparison with the daily $F_{\mathrm{va}}$ in the NG, the daily $F_{\mathrm{va}}$ was 15 times higher in the MS, nearly 10 times higher in the EC, and nearly 27 times higher in the ME (see Table 1). It is quite notable that the $F_{\text {eco }}$ and $F_{\text {va }}$ were all higher in 2013 than in 2012 in the PG with an exception in the EC where the $F_{\text {va }}$ was slightly lower in 2013 than in 2012.

Table 1 Daily mean respiration fluxes (after modification) in the four grassland types in 2012 (27 July to 5 August) and 2013 (18 July to 25 July)

\begin{tabular}{|c|c|c|c|c|c|}
\hline \multirow{2}{*}{ Year } & \multirow{2}{*}{ Grassland } & \multicolumn{4}{|c|}{ Respiration fluxes $\left(\mu \mathrm{mol} \mathrm{CO} \mathrm{CO}_{2} /\left(\mathrm{m}^{2} \cdot \mathrm{s}\right)\right)$} \\
\hline & & $F_{\text {eco }}$ & $F_{\text {va }}$ & $F_{\text {ts }}$ & $F_{\text {sh }}$ \\
\hline \multirow{4}{*}{2012} & NG & $12.71 \pm 0.67^{\mathrm{a}}$ & $5.65 \pm 0.30^{\mathrm{a}}$ & $7.65 \pm 0.26^{\mathrm{a}}$ & $7.07 \pm 0.49^{\mathrm{a}}$ \\
\hline & MS & $14.28 \pm 2.26^{b}$ & $9.09 \pm 1.49^{\mathrm{b}}$ & $6.98 \pm 0.65^{\mathrm{b}}$ & $5.19 \pm 0.90^{\mathrm{b}}$ \\
\hline & $\mathrm{EC}$ & $10.66 \pm 0.95^{\mathrm{c}}$ & $7.03 \pm 0.97^{\mathrm{c}}$ & $6.93 \pm 0.38^{\mathrm{b}}$ & $3.63 \pm 0.21^{\mathrm{c}}$ \\
\hline & ME & $10.53 \pm 0.60^{c}$ & $7.38 \pm 0.72^{\mathrm{c}}$ & $6.28 \pm 0.47^{\mathrm{c}}$ & $3.14 \pm 0.21^{\mathrm{c}}$ \\
\hline \multirow{4}{*}{2013} & NG & $8.43 \pm 0.62^{\mathrm{a}}$ & $0.67 \pm 0.39^{\mathrm{a}}$ & $8.28 \pm 1.00^{\mathrm{a}}$ & $7.53 \pm 0.79^{\mathrm{a}}$ \\
\hline & MS & $17.50 \pm 1.19^{\mathrm{b}}$ & $10.36 \pm 2.12^{\mathrm{b}}$ & $10.91 \pm 0.99^{\mathrm{b}}$ & $7.14 \pm 0.41^{\mathrm{a}}$ \\
\hline & $\mathrm{EC}$ & $11.82 \pm 1.19^{\mathrm{c}}$ & $6.47 \pm 0.98^{\mathrm{c}}$ & $9.68 \pm 0.30^{\mathrm{c}}$ & $5.34 \pm 0.22^{\mathrm{b}}$ \\
\hline & $\mathrm{ME}$ & $27.63 \pm 2.10^{\mathrm{d}}$ & $17.93 \pm 2.07^{\mathrm{d}}$ & $13.05 \pm 1.06^{\mathrm{d}}$ & $9.70 \pm 0.57^{\mathrm{c}}$ \\
\hline
\end{tabular}

Note: $F_{\text {eco }}$, ecosystem respiration; $F_{\text {ts }}$, total soil respiration; $F_{\text {sh }}$, soil heterotrophic respiration; $F_{\text {va }}$, vegetation autotrophic respiration. NG, natural grassland; MS, Medicago sativa grassland; EC, Elymus cylindricus grassland; ME, M. sativa + E. cylindricus grassland. Mean \pm SD. Values followed by different lowercase letters in the same column in 2012 (or 2013) indicate significant differences $(P<0.05$ ) among the four grassland types.

\subsection{Total soil respiration $\left(F_{\mathrm{ts}}\right)$ and soil heterotrophic respiration $\left(F_{\mathrm{sh}}\right)$}

In 2012 (27 July to 5 August), the daily variations of $F_{\text {ts }}$ in all four grassland types (including NG, MS, EC, and ME) were rather small, with most of the values ranging between 6 and $8 \mu \mathrm{mol}$ $\mathrm{CO}_{2} /\left(\mathrm{m}^{2} \cdot \mathrm{s}\right)$ (Fig. $\left.2 \mathrm{c}\right)$. The hourly $F_{\text {ts }}$ values in the PG (MS, EC, and ME) were slightly lower than those in the NG after 12:00 (Fig. 2c) and the daily mean $F_{\text {ts }}$ in the NG was higher than those in the PG (Table 1). In contrast, the hourly $F_{\text {sh }}$ values in the PG were all lower than those in the NG during the entire observation period, with the difference between NG and PG becoming larger in the afternoon (Fig. 2d). Being similar with the daily mean $F_{\text {ts }}$, the daily mean $F_{\text {sh }}$ in the NG was also higher than those in the PG (see Table 1).

In 2013 (18 July to $25 \mathrm{July}$ ), the daily variations of $F_{\mathrm{ts}}$ in all grasslands (including NG, MS, EC, and ME) were also small, with most of the values ranging between 8 and $12 \mu \mathrm{mol} \mathrm{CO} /\left(\mathrm{m}^{2} \cdot \mathrm{s}\right)(\mathrm{Fig}$. $2 \mathrm{~g}$ ). The hourly $F_{\text {ts }}$ values in the PG (MS, EC, and ME) were higher than those in the NG almost during the entire observation period (Fig. $2 \mathrm{~g}$ ) and consequently, the daily mean $F_{\text {ts }}$ in the NG was the lower than those in the PG (see Table 1 ). In comparison, the hourly $F_{\text {sh }}$ values did not follow the same patterns as the hourly $F_{\text {ts }}$ values. Specifically, the daily $F_{\text {sh }}$ values in the NG were always lower than those in the ME and always higher than those in the EC during the entire observation period (Fig. 2h), whereas the hourly $F_{\text {sh }}$ values in the MS were higher than those in the NG only in the early afternoon (i.e., around 14:00). It is also notable that both the $F_{\text {ts }}$ and $F_{\text {sh }}$ were considerably higher in 2013 than in 2012 in the PG (MS, EC, and ME).

\subsection{Contribution of each of the three components $\left(F_{\text {sh }}, F_{\text {va }}\right.$, and $\left.F_{\text {ts }}\right)$ to $F_{\text {eco }}$}

In 2012 (27 July to 5 August), the contribution of daily mean $F_{\text {sh }}$ to daily mean $F_{\text {eco }}$ was $56 \%$ in the NG (Table 1), while the contribution was only $33 \%$ in the PG (i.e., $36 \%, 34 \%$, and $30 \%$ in the 
MS, EC, and ME, respectively). In contrast, the contribution of daily mean $F_{\text {va }}$ to daily mean $F_{\text {eco }}$ was lower in the NG (44\%) than in the PG (MS, EC, and ME) $(>64 \%)$. The results demonstrated that $F_{\text {sh }}$ contributed more to $F_{\text {eco }}$ in the NG while $F_{\text {va }}$ contributed more to $F_{\text {eco }}$ in the PG. Furthermore, the contributions of daily mean $F_{\text {sh }}$ to daily mean $F_{\text {ts }}$ were all higher than $50 \%$ in the four grassland types (including NG, MS, EC, and ME), which indicated that $F_{\text {sh }}$ contributed more to $F_{\mathrm{ts}}$ than root respiration in all four grassland types.

In 2013 (18 July to 25 July), the contribution of daily mean $F_{\text {sh }}$ to daily mean $F_{\text {eco }}$ was $92 \%$ in the NG (see Table 1), while the contribution was only $40 \%$ in the PG (i.e., $41 \%, 45 \%$, and $35 \%$ in the MS, EC, and ME, respectively). In contrast, the contribution of daily mean $F_{\mathrm{va}}$ to daily mean $F_{\text {eco }}$ was significantly lower in the NG $(8 \%)$ than in the PG $(>55 \%)$. The results also demonstrated that $F_{\text {sh }}$ contributed more to $F_{\text {eco }}$ in the NG while $F_{\text {va }}$ contributed more to $F_{\text {eco }}$ in the PG. Furthermore, the contributions of daily mean $F_{\text {sh }}$ to daily mean $F_{\text {ts }}$ were all higher than $50 \%$ in the four grassland types (including NG, MS, EC, and ME), which also indicated that $F_{\text {sh }}$ contributed more to $F_{\text {ts }}$ than root respiration in the four grassland types.

\section{Discussion}

\subsection{Variations of $\boldsymbol{F}_{\text {eco }}$ and its components caused by land-use changes}

Land-use changes strongly influence the global carbon dynamics (Aslam et al., 2000; Kim and Kirschbaum, 2015) through altering the respiration fluxes of ecosystems (Valentini et al., 2000; Zhang et al., 2012). Our results showed that $F_{\text {eco }}$ in the NG was significantly different from those in the PG (including MS, EC, and ME; $P<0.05$ ) and $F_{\text {eco }}$ in the PG was higher than that in the NG (see Fig. 2; Table 1), being consistent with the results of Qi et al. (2007). Furthermore, $F_{\mathrm{ts}}, F_{\mathrm{sh}}$ and $F_{\text {va }}$ in the NG were all significantly different from those in the PG $(P<0.05$; Table 1$)$, and they were higher in the PG than in the NG in most cases, being supportive to the result of Rong et al. (2015). These results indicate that the conversion of natural grasslands into planted grasslands can significantly enhance the fluxes of $F_{\text {eco }}$ and its components. Almost all the respiration fluxes were higher in 2013 (2-year plantation) than in 2012 (1-year plantation) in the planted grasslands, further confirming the point that the age or maturity of the planted grasslands can greatly influence the respiration fluxes (Qi et al., 2007; Xu et al., 2009; Pang et al., 2011; Zhang et al., 2012). The results also showed that the contribution of daily mean $F_{\text {sh }}$ to $F_{\text {eco }}$ was higher in the NG than in the PG both in 2012 and 2013, while the contribution of daily mean $F_{\text {va }}$ to $F_{\text {eco }}$ exhibited an opposite pattern. However, the observation period of this study was admittedly too short. To more fully understand the effects of such land-use changes (i.e., the conversion of natural grasslands into planted grasslands) on respiration fluxes, longer-term observations are badly needed.

Generally speaking, it is difficult to obtain a more accurate $F_{\text {sh }}$ because distinguishing $F_{\text {sh }}$ from root respiration is difficult (Hanson et al., 2000; Kuzyakov and Larionova, 2005). Several methods/approaches, such as isotopic method (Casals et al., 2011), trenching (Li et al., 2013; Tomotsune et al., 2013), root biomass regression analysis (Tomotsune et al., 2013), and root excision (Peng et al., 2015), were used to distinguish $F_{\mathrm{sh}}$ from root respiration. But, each approach has its merits and demerits (Hanson et al., 2000; Kuzyakov and Larionova, 2005). Thus, appropriate method/approach should be selected in accordance with the field conditions. In the present study, there was almost no root distributed in the bare soil and $F_{\text {sh }}$ was therefore directly measured on the bare soil to avoid soil disturbance (i.e., separating the roots from the soil), improving the measurement accuracy.

\subsection{Relationships between respiration fluxes and environmental factors}

4.2.1 Relationships of respiration fluxes with air temperature and humidity and soil temperature and moisture

The environmental requirements of plant growth differ among species because of different physiological and ecological properties (Sánchez et al., 2002). In the present study, the species composition, and physiological and ecological properties of plants, as well as microhabitats, greatly differed among the natural and planted grasslands, and these differences may influence the 
respiration fluxes. Thus, we selected the optimal regression equations to describe the relationships of respiration fluxes with air temperature and humidity and soil temperature and moisture (Tables 2-4).

Table 2 Relationships of ecosystem respiration $\left(F_{\text {eco }}\right)$ with air temperature and air humidity in the four grassland types in 2012 (27 July to 5 August) and 2013 (18 July to 25 July)

\begin{tabular}{clll}
\hline Year $\quad$ Grassland & \multicolumn{1}{c}{ Air temperature } & \multicolumn{1}{c}{ Relative humidity } \\
\hline NG & $y=0.365 x+4.291\left(R^{2}=0.335, P=0.038\right)$ & $y=-0.123 x+19.412\left(R^{2}=0.615, P=0.001\right)$ \\
MS & $y=1.032 x-6.641\left(09: 00-13: 00 ; R^{2}=0.975, P=0.002\right)$ & $y=-0.283 x+33.943\left(09: 00-13: 00 ; R^{2}=0.927, P=0.009\right)$ \\
& & $y=1.382 x-22.840\left(14: 00-19: 00 ; R^{2}=0.801, P=0.040\right)$ & $y=-0.301 x+28.623\left(14: 00-19: 00 ; R^{2}=0.696, P=0.039\right)$ \\
EC & $y=0.577 x-3.083\left(R^{2}=0.693, P<0.001\right)$ & $y=-0.148 x+20.138\left(R^{2}=0.603, P=0.002\right)$ \\
ME $\quad y=0.326 x+3.305\left(07: 00-13: 00 ; R^{2}=0.659, P=0.050\right)$ & $y=-0.068 x+15.209\left(07: 00-13: 00 ; R^{2}=0.574, P=0.048\right)$ \\
& $y=0.693 x-7.371\left(14: 00-19: 00 ; R^{2}=0.710, P=0.035\right)$ & $y=-0.226 x+22.255\left(14: 00-19: 00 ; R^{2}=0.789, P=0.044\right)$ \\
NG $\quad y=1.199 \exp (0.084 x)\left(R^{2}=0.874, P<0.001\right)$ & $y=-0.153 x+16.325\left(R^{2}=0.770, P<0.001\right)$ \\
MS $\quad y=0.631 x+5.473\left(07: 00-13: 00 ; R^{2}=0.686, P=0.021\right)$ & $y=-0.152 x+27.345\left(07: 00-13: 00 ; R^{2}=0.810, P=0.006\right)$ \\
& $y=1.308 x-14.465\left(14: 00-19: 00 ; R^{2}=0.679, P=0.086\right)$ & $y=-0.365 x+31.871\left(14: 00-19: 00 ; R^{2}=0.680, P=0.175\right)$ \\
EC $\quad y=0.964 x-10.793\left(R^{2}=0.825, P<0.001\right)$ & $y=-0.164 x+21.293\left(R^{2}=0.669, P=0.001\right)$ \\
ME $\quad y=0.852 x+11.405\left(07: 00-12: 00 ; R^{2}=0.844, P=0.027\right)$ & $y=-0.176 x+38.103\left(07: 00-13: 00 ; R^{2}=0.777, P=0.004\right)$ \\
& $y=0.086 \exp (0.239 x)\left(13: 00-19: 00 ; R^{2}=0.695\right.$, & $y=85.328 \exp (-0.031 x)\left(14: 00-19: 00 ; R^{2}=0.689\right.$, \\
& $P=0.039)$ & $P=0.041)$
\end{tabular}

Note: In the regression equations, $y$ represents $F_{\text {eco }}$ and $x$ represents air temperature or relative humidity. Times shown in brackets represent the time periods used in the piecewise regressions, whereas the others (times do not shown in brackets) represent that the time periods used in the piecewise regressions were from 06:00 to 20:00.

Table 3 Relationships of total soil respiration $\left(F_{\mathrm{ts}}\right)$ with soil temperature and soil moisture in the four grassland types in 2012 (27 July to 5 August) and 2013 (18 July to 25 July)

\begin{tabular}{|c|c|c|c|}
\hline Year & Grassland & Soil temperature & Soil moisture \\
\hline \multirow{5}{*}{2012} & \multirow{2}{*}{ NG } & \multirow{2}{*}{$y=-0.040 x^{2}+1.901 x-14.656\left(R^{2}=0.528, P=0.023\right)$} & $y=3.77 x-64.296\left(07: 00-14: 00 ; R^{2}=0.800, P=0.003\right)$ \\
\hline & & & $y=(1.297 \mathrm{E}-12) \exp 1.506 x\left(15: 00-19: 00 ; R^{2}=0.645, P=0.102\right)$ \\
\hline & MS & $y=-0.100 x^{2}+4.111 x-35.110\left(R^{2}=0.843, P=0.001\right)$ & $y=-0.099 x^{3}+104.725 x-1302\left(R^{2}=0.657, P=0.014\right)$ \\
\hline & $\mathrm{EC}$ & $y=-0.060 x^{2}+2.897 x-27.296\left(R^{2}=0.851, P<0.001\right)$ & $y=-0.094 x^{3}+94.119 x-1139\left(R^{2}=0.719, P=0.001\right)$ \\
\hline & ME & $y=-0.004 x^{2}+0.335 x+0.090\left(R^{2}=0.670, P=0.004\right)$ & $y=2.320 x-36.246\left(R^{2}=0.706, P<0.001\right)$ \\
\hline \multirow{4}{*}{2013} & NG & $y=0.024 x^{2}-0.940 x+16.655\left(R^{2}=0.851, P<0.001\right)$ & $y=0.016 x^{2}-0.507 x+11.451\left(R^{2}=0.823, P<0.001\right)$ \\
\hline & MS & $y=0.010 x^{2}-0.168 x+7.058\left(R^{2}=0.969, P<0.001\right)$ & $y=-0.012 x^{2}+1.025 x-4.543\left(R^{2}=0.780, P=0.001\right)$ \\
\hline & $\mathrm{EC}$ & $y=0.004 x^{2}-0.008 x+6.681\left(R^{2}=0.848, P<0.001\right)$ & $y=-0.133 x^{2}+5.209 x-40.957\left(R^{2}=0.664, P=0.007\right)$ \\
\hline & ME & $y=0.031 x^{2}-1.346 x+25.926\left(R^{2}=0.530, P=0.023\right)$ & $y=0.154 x^{2}-5.919 x+68.643\left(R^{2}=0.104, P=0.579\right)$ \\
\hline
\end{tabular}

Note: In the regression equations, $y$ represents $F_{\mathrm{ts}}$ and $x$ represents soil temperature or soil moisture. Times shown in brackets represent the time periods used in the piecewise regressions, whereas the others (times do not shown in brackets) represent that the time periods used in the piecewise regressions were from 06:00 to 20:00.

Table 4 Relationships of soil heterotrophic respiration $\left(F_{\text {sh }}\right)$ with soil temperature and soil moisture in the four grassland types in 2012 (27 July to 5 August) and 2013 (18 July to 25 July)

\begin{tabular}{rlll}
\hline Year & Grassland & \multicolumn{1}{c}{ Soil temperature } & \multicolumn{1}{c}{ Soil moisture } \\
\hline & NG & $y=-0.021 x^{2}+1.126 x-6.681\left(R^{2}=0.704, P=0.002\right)$ & $y=2.530 x-40.884\left(R^{2}=0.637, P=0.001\right)$ \\
2012 & MS & $y=-0.061 x^{2}+2.281 x-15.534\left(R^{2}=0.835, P=0.001\right)$ & $y=-0.296 x^{3}+306.396 x-3787\left(R^{2}=0.737, P=0.005\right)$ \\
& EC & $y=-0.033 x^{2}+1.520 x-13.625\left(R^{2}=0.561, P=0.025\right)$ & $y=-0.042 x^{3}+41.893 x-503.148\left(R^{2}=0.407, P=0.124\right)$ \\
& ME & $y=-0.005 x^{2}+0.297 x-1.335\left(R^{2}=0.706, P=0.002\right)$ & $y=1.036 x-15.800\left(R^{2}=0.675, P=0.001\right)$ \\
& NG & $y=0.011 x^{2}-0.182 x+4.733\left(R^{2}=0.860, P<0.001\right)$ & $y=0.024 x^{2}-0.642 x+9.083\left(R^{2}=0.927, P<0.001\right)$ \\
MS & $y=0.144 x+3.001\left(R^{2}=0.534, P=0.005\right)$ & $y=0.003 x^{2}+0.133 x+2.775\left(R^{2}=0.896, P<0.001\right)$ \\
& EC & $y=0.670 x+3.562\left(R^{2}=0.488, P=0.011\right)$ & $y=0.013 x^{2}-0.410 x+7.875\left(R^{2}=0.872, P<0.001\right)$ \\
& ME & $y=0.300 x+1.332\left(R^{2}=0.544, P=0.004\right)$ & $y=0.143 x^{2}-5.514 x+61.597\left(R^{2}=0.100, P=0.591\right)$
\end{tabular}

Note: In the regression equations, $y$ represents $F_{\mathrm{sh}}$ and $x$ represents soil temperature or soil moisture. The time periods used in the piecewise regressions were all from 06:00 to 20:00. 
Both air temperature and relative humidity showed significant relationships with $F_{\text {eco }}$ in all grasslands (including NG, MS, EC, and ME) in the two experimental periods. Regression relationships of $F_{\text {eco }}$ with air temperature and relative humidity in the MS and ME showed that respiration from $M$. sativa is more sensitive to air temperature and relative humidity compared to E. cylindricus. This may be due to the larger leaf area index and higher sensitivity of photosynthesis of $M$. sativa species.

Our regression analyses revealed that soil temperature and soil moisture could respectively explain about $73 \%$ and $74 \%$ of the daily variations of soil respiration (data not shown), being rather similar with the results reported by others (e.g., Ma, 2008; Wang et al., 2016). In the present study, soil temperature and soil moisture exerted the same effects on soil respiration in most cases (see Tables 3 and 4). However, no consensus has been reached regarding the relative importance of soil temperature and soil moisture to soil respiration because the environmental conditions may vary greatly from region to region (Cao et al., 2004; Liu et al., 2009; Li et al., 2013; Peri et al., 2015; Sharkhuu et al., 2016; Wang et al., 2016).

\subsubsection{Relationships of respiration fluxes with vegetation}

Land-use changes can alter the aboveground biomass, root biomass and leaf area index, which may in turn influence the $F_{\text {eco }}$ and its components (Zhang et al., 2012; Borchard et al., 2015). Frank et al. (2006) reported that the conversion of natural grassland to cropland could increase $F_{\text {ts }}$ due to high root biomass and frequent soil disturbance by cultivation that provided an abundant carbon supply for soil microbial activity. In this study, we found that there was no significant correlations $(r=0.42, P>0.05)$ between $F_{\text {eco }}$ and aboveground biomass in all grasslands, natural or planted. However, with increasing plantation age, the $F_{\text {eco }}$, as well as aboveground biomass, in the PG (MS, EC, and ME) increased (Fig. 3). The $F_{\text {eco }}$ in the ME was the highest. This may be caused by the interactions (e.g., $M$. sativa is a legume species that can fix nitrogen, thus it can improve the growth and metabolism of the multi-species plantation) and the competitions (struggling for more water and light) between $M$. sativa and E. cylindricus.

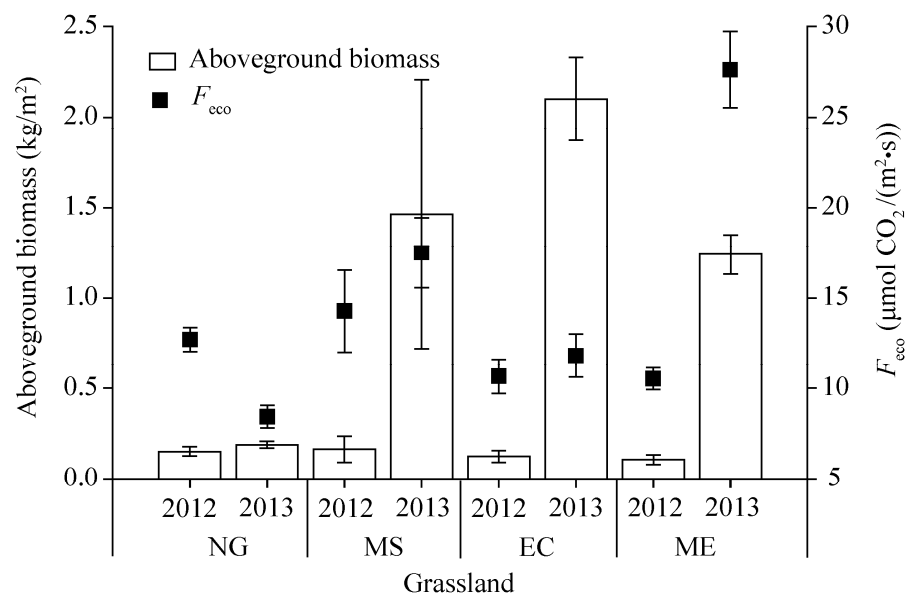

Fig. 3 Aboveground biomass and ecosystem respiration $\left(F_{\text {eco }}\right)$ in the four grassland types (NG, MS, EC, and ME) in 2012 (27 July to 5 August) and 2013 (18 July to 25 July). Bars mean standard errors; $n=3$.

4.2.3 Relationships of respiration fluxes with soil bulk density and SOC

During the establishment of planted grasslands, soil tillage could change the degree of soil aggregation. Specifically, soil aggregation would decrease after the conversion of natural grasslands into planted grasslands, which may result in a decrease in soil bulk density. The decrease in soil density may in turn influence the carbon fluxes by changing the carbonate dissolution chemistry and surface adhesion of carbonates to soil particles (Sánchez et al., 2002; Dieckow et al., 2005; Ball et al., 2009). In this study, we found that there was a slightly positive correlation between $F_{\text {sh }}$ and soil bulk density $(r=0.50, P>0.05$; Fig. 4), and our result was 
consistent with the result of Ball et al. (2009).

SOC content in the NG was a slightly higher than those in the PG (MS, EC, and ME) in 2012 but significantly lower than those in the PG in 2013 (data not shown), indicating that the establishment of planted grasslands may decrease SOC content and that the maturity of planted grasslands may increase SOC content, and our results were similar with the results of Kainiemi et al. (2013). There was a significant positive correlation between $F_{\text {ts }}$ and SOC content $(r=0.57$, $P<0.05$; Fig. 5), and our result was in agreement with the results of Wang et al. (2003) and Regina and Alakukku (2010). The aforementioned results indicate that the conversion of natural grasslands into planted grasslands could significantly affect the respiration fluxes through changing SOC.

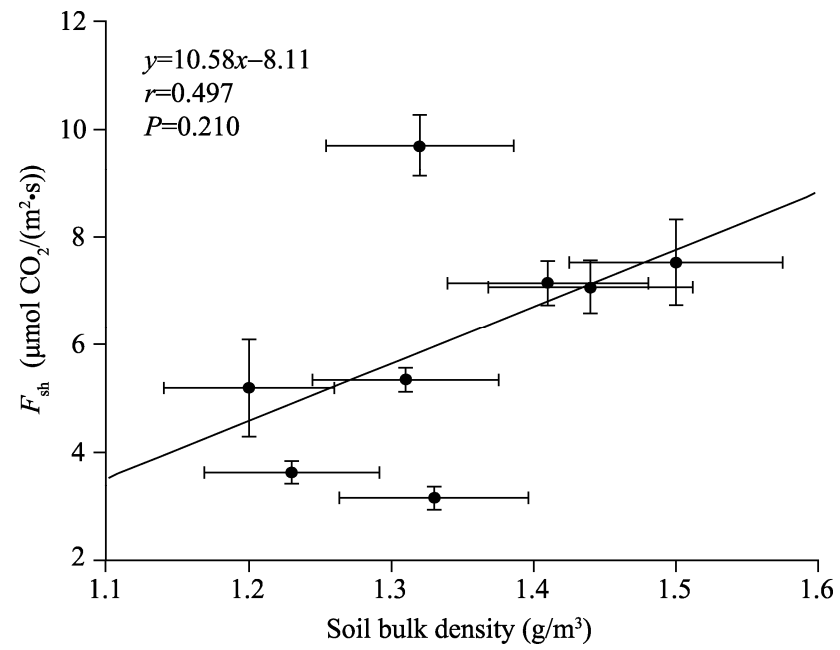

Fig. 4 Relationship of soil heterotrophic respiration $\left(F_{\mathrm{sh}}\right)$ and soil bulk density to a depth of $10 \mathrm{~cm}$. Bars mean standard errors; $n=3$.

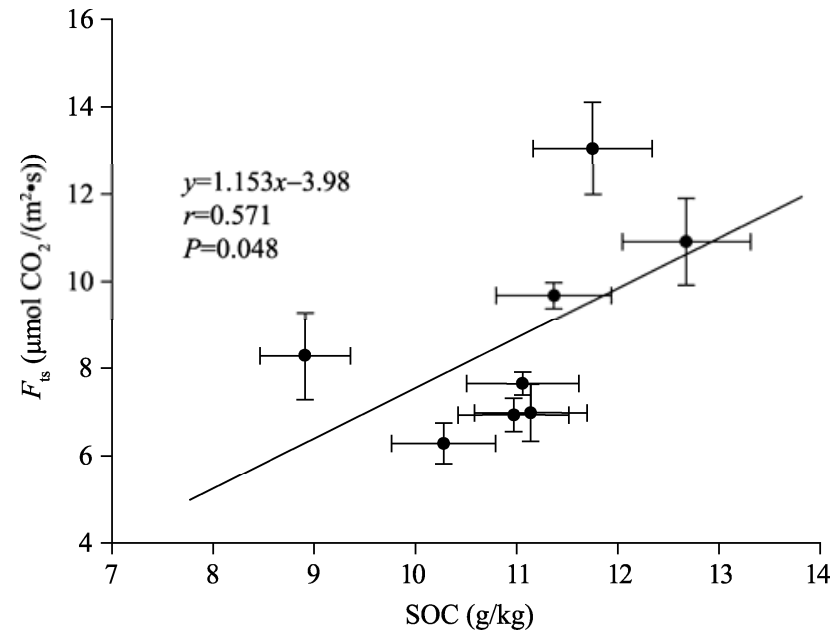

Fig. 5 Relationship of total soil respiration $\left(F_{\mathrm{ts}}\right)$ and soil organic carbon (SOC) content to a depth of $10 \mathrm{~cm}$. Bars mean standard errors; $n=3$.

\section{Conclusions}

In this study, we compared the respiration fluxes $\left(F_{\text {eco }}, F_{\mathrm{ts}}, F_{\mathrm{sh}}\right.$, and $\left.F_{\mathrm{va}}\right)$ between one type of natural grassland (NG) and three types of planted grasslands (MS, EC, and ME) and analyzed the relationships between respiration fluxes (i.e., $F_{\mathrm{eco}}, F_{\mathrm{ts}}, F_{\mathrm{sh}}$, and $F_{\mathrm{va}}$ ) and environmental factors (i.e., soil properties, vegetation and climate factors) in those grasslands. The initial observed carbon 
fluxes were modified by environmental factors to ensure the comparability between different measurements in terms of the environmental conditions among different grassland types.

Generally speaking, all the respiration fluxes were increased after the conversion of natural grasslands into planted grasslands, especially in the second experimental year (i.e., 2013). And, $F_{\text {sh }}$ contributed more to $F_{\text {eco }}$ in the NG while $F_{\text {va }}$ contributed more to $F_{\text {eco }}$ in the planted grasslands. Climate factors (air temperature and relative humidity) and soil properties (SOC, soil temperature, and soil moisture) strongly affected the respiration fluxes in all grasslands, natural and planted. Here, we suggest that modification of initial observed carbon fluxes, using appropriate methods/approaches for distinguishing $F_{\mathrm{sh}}$ and root respiration from $F_{\mathrm{ts}}$, should be adopted and that longer-term observation should be considered in future researches.

\section{Acknowledgments}

This study was supported by the National Basic Research Program of China (2014CB138803), the National Natural Science Foundation of China (31570451), and the Program for Changjiang Scholars and Innovative Research Team in University (IRT1108). We thank the staff of the Duolun Grassland Research Station, Inner Mongolia, and LIN Guohui and ZHAO Shijie for their help during the field observations.

\section{References}

Aslam T, Choudhary M A, Saggar S. 2000. Influence of land-use management on $\mathrm{CO}_{2}$ emissions from a silt loam soil in New Zealand. Agriculture, Ecosystems \& Environment, 77(3): 257-262.

Ball B A, Virginia R A, Barrett J E, et al. 2009. Interactions between physical and biotic factors influence $\mathrm{CO}_{2}$ flux in Antarctic dry valley soils. Soil Biology and Biochemistry, 41(7): 1510-1517.

Borchard N, Schirrmann M, Hebel C V, et al. 2015. Spatio-temporal drivers of soil and ecosystem carbon fluxes at field scale in an upland grassland in Germany. Agriculture, Ecosystems \& Environment, 211: 84-93.

Bremer D J, Ham J M, Owensby C E, et al. 1998. Responses of soil respiration to clipping and grazing in a tallgrass prairie. Journal of Environmental Quality, 27(6): 1539-1548.

Brito L F, Azenha M V, Janusckiewicz E R, et al. 2015. Seasonal fluctuation of soil carbon dioxide emission in differently managed pastures. Agronomy Journal, 107(3): 957-962.

Cao G M, Tang Y H, Mo W H, et al. 2004. Grazing intensity alters soil respiration in an alpine meadow on the Tibetan plateau. Soil Biology and Biochemistry, 36(2): 237-243.

Casals P, Lopez-Sangil L, Carrara A, et al. 2011. Autotrophic and heterotrophic contributions to short-term soil $\mathrm{CO}_{2}$ efflux following simulated summer precipitation pulses in a Mediterranean dehesa. Global Biogeochemical Cycles, 25(3): GB3012, doi: 10.1029/2010GB003973.

Chen H Q, Fan M S, Kuzyakov Y, et al. 2014. Comparison of net ecosystem $\mathrm{CO}_{2}$ exchange in cropland and grassland with an automated closed chamber system. Nutrient Cycling in Agroecosystems, 98(2): 113-124.

Dai E F, Huang Y, Wu Z, et al. 2016. Analysis of spatio-temporal features of a carbon source/sink and its relationship to climatic factors in the Inner Mongolia grassland ecosystem. Journal of Geographical Sciences, 26(3): $297-312$.

Davidson B A, Belk E, Boone R D. 1998. Soil water content and temperature as independent or confounded factors controlling soil respiration in a temperate mixed hardwood forest. Global Change Biology, 4(2): 217-227.

Deng F, Li X B, Wang H, et al. 2014. GIS-based assessment of land suitability for alfalfa cultivation: A case study in the dry continental steppes of northern China. Spanish Journal of Agricultural Research, 12(2): 364-375.

Diekow J, Mielniczuk J, Knicker H, et al. 2005. Carbon and nitrogen stocks in physical fractions of a subtropical Acrisol as influenced by long-term no-till cropping systems and N fertilisation. Plant and Soil, 268(1): 319-328.

Fang C, Moncrieff J B. 2001. The dependence of soil $\mathrm{CO}_{2}$ efflux on temperature. Soil Biology and Biochemistry, 33(2): 155-165.

Flanagan L B, Johnson B G. 2005. Interacting effects of temperature, soil moisture and plant biomass production on ecosystem respiration in a northern temperate grassland. Agricultural and Forest Meteorology, 130(3-4): 237-253.

Frank A B, Liebig M A, Tanaka D L. 2006. Management effects on soil $\mathrm{CO}_{2}$ efflux in northern semiarid grassland and cropland. Soil and Tillage Research, 89(1): 78-85.

Gomez-Casanovas N, Matamala R, Cook D R, et al. 2012. Net ecosystem exchange modifies the relationship between the autotrophic and heterotrophic components of soil respiration with abiotic factors in prairie grasslands. Global Change Biology, 18(8): 2532-2545. 
Gong J R, Wang Y H, Liu M, et al. 2014. Effects of land use on soil respiration in the temperate steppe of Inner Mongolia, China. Soil and Tillage Research, 144: 20-31.

Grace J, Rayment M. 2000. Respiration in the balance. Nature, 404(6780): 819-820.

Han Y, Zhang Z, Wang C H, et al. 2012. Effects of mowing and nitrogen addition on soil respiration in three patches in an oldfield grassland in Inner Mongolia. Journal of Plant Ecology, 5(2): 219-228.

Hanson P J, Edwards N T, Garten C T, et al. 2000. Separating root and soil microbial contributions to soil respiration: A review of methods and observations. Biogeochemistry, 48(1): 115-146.

Holst J, Liu C, Yao Z, et al. 2008. Fluxes of nitrous oxide, methane and carbon dioxide during freezing-thawing cycles in an Inner Mongolian steppe. Plant and Soil, 308(1-2): 105-117.

Holthausen R S, Caldwell M M. 1980. Seasonal dynamics of root system respiration in Atriplex confertifolia. Plant and Soil, 55(2): 307-317.

IPCC (Intergovernmental Panel on Climate Change). 2007. Summary for policymakers. In: Solomon S, Qin D, Manning M, et al. Climate Change 2007: The Physical Science Basis. Contribution of Working Group I to the Fourth Assessment Report of the Intergovernmental Panel on Climate Change. Cambridge, United Kingdom, New York, NY, USA: Cambridge University Press.

Jenkinson D S. 1990. The turnover of organic carbon and nitrogen in soil. Philosophical Transactions of the Royal Society B: Biological Sciences, 329(1255): 361-368.

Kainiemi V, Arvidsson J, Kätterer T. 2013. Short-term organic matter mineralisation following different types of tillage on a Swedish clay soil. Biology and Fertility of Soils, 49(5): 495-504.

Kim D G, Kirschbaum M U F. 2015. The effect of land-use change on the net exchange rates of greenhouse gases: A compilation of estimates. Agriculture, Ecosystems \& Environment, 208: 114-126.

Kuzyakov Y V, Larionova A A. 2005. Root and rhizomicrobial root respiration: A review of approaches to estimate respiration by autotrophic and heterotrophic organisms in soil. Journal of Plant Nutrition and Soil Science, 168(4): 503-520.

Lal R. 2004. Soil carbon sequestration to mitigate climate change. Geoderma, 123(1-2): 1-22.

Li X B, Li G Q, Wang H, et al. 2015. Influence of meadow changes on net primary productivity: A case study in a typical steppe area of XilinGol of Inner Mongolia in China. Geosciences Journal, 19(3): 561-573.

Li X D, Zhang C P, Fu H, et al. 2013. Grazing exclusion alters soil microbial respiration, root respiration and the soil carbon balance in grasslands of the Loess Plateau, northern China. Soil Science and Plant Nutrition, 59(6): 877-887.

Liu W X, Zhang Z, Wan S Q. 2009. Predominant role of water in regulating soil and microbial respiration and their responses to climate change in a semiarid grassland. Global Change Biology, 15(1): 184-195.

Liu X Z, Wan S O, Su B, et al. 2002. Response of soil $\mathrm{CO}_{2}$ efflux to water manipulation in a tallgrass prairie ecosystem. Plant and Soil, 240(2): 213-223.

Lu X Y, Fan J H, Yan Y, et al. 2013. Responses of soil $\mathrm{CO}_{2}$ fluxes to short-term experimental warming in alpine steppe ecosystem, Northern Tibet. PLoS ONE, 8(3): e59054, doi:10.1371/journal.pone.0059054.

Ma T. 2008. Effect of grazing on soil respiration in typical Leymus chinensis grassland of Xilin River basin in Inner Mongolia. MSc Thesis. Yangling: Northwest A\&F University. (in Chinese)

MacDonald N W, Zak D R, Pregitzer K S. 1995. Temperature effects on kinetics of microbial respiration and net nitrogen and sulfur mineralization. Soil Science Society of America Journal, 59(1): 233-240.

Mielnick P C, Dugas W A. 2000. Soil $\mathrm{CO}_{2}$ flux in a tallgrass prairie. Soil Biology and Biochemistry, 32(2): 221-228.

Monkany K, Raison R J, Prokushkin A S. 2006. Critical analysis of root: Shoot ratios in terrestrial biomes. Global Change Biology, 12(1): 84-96.

Pang Y Y, Deng B, Zhang Y J, et al. 2011. Soil respiration of alfalfa fields in the agro-pastoral ecotone of Northern China and its environment on responses. Acta Agrestia Sinica, 19(3): 432-437. (in Chinese)

Pendall E, Schwendenmann L, Rahn T, et al. 2010. Land use and season affect fluxes of $\mathrm{CO}_{2}, \mathrm{CH}_{4}, \mathrm{CO}, \mathrm{N}_{2} \mathrm{O}, \mathrm{H}_{2}$ and isotopic source signatures in Panama: Evidence from nocturnal boundary layer profiles. Global Change Biology, 16(10): 2721-2736.

Peng F, You Q G, Xu M H, et al. 2015. Effects of experimental warming on soil respiration and its components in an alpine meadow in the permafrost region of the Qinghai-Tibet Plateau. European Journal of Soil Science, 66(1): 145-154.

Peri P L, Bahamonde H, Christiansen R. 2015. Soil respiration in Patagonian semiarid grasslands under contrasting environmental and use conditions. Journal of Arid Environments, 119: 1-8.

Qi Y C, Dong Y S, Liu J Y, et al. 2007. Effect of the conversion of grassland to spring wheat field on the $\mathrm{CO}_{2}$ emission characteristics in Inner Mongolia, China. Soil and Tillage Research, 94(2): 310-320.

Regina K, Alakukku L. 2010. Greenhouse gas fluxes in varying soil types under conventional and no-till practices. Soil and Till Research, 109(2): 144-152. 
Reichstein M, Falge E, Baldocchi D, et al. 2005. On the separation of net ecosystem exchange into assimilation and ecosystem respiration: Review and improved algorithm. Global Change Biology, 11(9): 1424-1439.

Rochette P, Desjardins R L, Pattey E. 1991. Spatial and temporal variability of soil respiration in agricultural fields. Canadian Journal of Soil Science, 71(2): 189-196.

Rong Y P, Ma L, Johnson D A, et al. 2015. Soil respiration patterns for four major land-use types of the agro-pastoral region of northern China. Agriculture, Ecosystems \& Environment, 213: 142-150.

Sánchez M L, Ozores M I, Colle R, et al. 2002. Soil $\mathrm{CO}_{2}$ fluxes in cereal land use of the Spanish plateau: Influence of conventional and reduced tillage practices. Chemosphere, 47(8): 837-844.

Schlentner R E, Van Cleve K. 1985. Relationships between $\mathrm{CO}_{2}$ evolution from soil, substrate temperature, and substrate moisture in four mature forest types in interior Alaska. Canadian Journal of Forest Research, 15(1): 97-106.

Sharkhuu A, Plante A F, Enkhmandal O, et al. 2016. Soil and ecosystem respiration responses to grazing, watering and experimental warming chamber treatments across topographical gradients in northern Mongolia. Geoderma, 269: 91-98.

Thierron V, Laudelout H. 1996. Contribution of root respiration to total $\mathrm{CO}_{2}$ efflux from the soil of a deciduous forest. Canadian Journal of Forest Research, 26(7): 1142-1148.

Tomotsune M, Yoshitake S, Watanabe S, et al. 2013. Separation of root and heterotrophic respiration within soil respiration by trenching, root biomass regression, and root excising methods in a cool-temperate deciduous forest in Japan. Ecological Research, 28(2): 259-269.

Valentini R, Matteucci G, Dolman A J, et al. 2000. Respiration as the main determinant of carbon balance in European forests. Nature, 404(6780): 861-865.

Varella R F, Bustamante M M C, Pinto A S, et al. 2004. Soil fluxes of $\mathrm{CO}_{2}, \mathrm{CO}, \mathrm{NO}$, and $\mathrm{N}_{2} \mathrm{O}$ from an old pasture and from native Savanna in Brazil. Ecological Applications, 14(4): 221-231.

Walkley A, Black I A. 1934. An examination of the Degtjareff method for determining soil organic matter and a proposed modification of the chromic acid titration method. Soil Science, 37(1): 29-38.

Wang C K, Jiang J Y, Zhang Q Z. 2006. Soil respiration in six temperate forests in China. Global Change Biology, 12(11): 2103-2114.

Wang W J, Dalal R C, Moody P W, et al. 2003 Relationships of soil respiration to microbial biomass, substrate availability and clay content. Soil Biology and Biochemistry, 35(2): 273-284.

Wang Y S, Hu Y O, Ji B M, et al. 2003. An investigation on the relationship between emission/uptake of greenhouse gases and environmental factors in semiarid grassland. Advances in Atmospheric Sciences, 20(1): 119-127.

Wang Z, Ji L, Hou X Y, et al. 2016. Soil respiration in semiarid temperate grasslands under various land management. PLoS ONE, 11(1): e0147987, doi: 10.1371/journal. pone.0147987.

$\mathrm{Wu} \mathrm{X}$, Yao Z, Brüggemann N, et al. 2010. Effects of soil moisture and temperature on $\mathrm{CO}_{2}$ and $\mathrm{CH}_{4}$ soil-atmosphere exchange of various land use/cover types in a semi-arid grassland in Inner Mongolia, China. Soil Biology and Biochemistry, 42(5): 773-787.

Xie H H, Fan J, Qi L B, et al. 2010. Seasonal characteristics of soil respiration and affecting factors under typical vegetations in the water-wind erosion crisscross region of the Loess Plateau. Environmental Science, 31(12): 2995-3003. (in Chinese)

Xie R, Wu X Q. 2016. Effects of grazing intensity on soil organic carbon of rangelands in Xilin Gol League, Inner Mongolia, China. Journal of Geographical Sciences, 26(11): 1550-1560.

Xu L J, Wang B, Yu Z, et al. 2009. Soil respiration in fields of Medicago sativa L. cv. Aohan with different growth years. Arid Zone Research, 26(1): 14-20. (in Chinese)

Yang J, Huang J H, Zhan X M, et al. 2004. The diurnal dynamic patterns of soil respiration for different plant communities in the agro-pastoral ecotone with reference to different measuring methods. Acta Phytoecologica Sinica, 28(3): 318-325. (in Chinese)

Zhan J Y, Yan H M, Chen B, et al. 2012. Decomposition analysis of the mechanism behind the spatial and temporal patterns of changes in carbon bio-sequestration in China. Energies, 5(2): 386-398.

Zhang X S, Tang H P, Dong X B, et al. 2016. The dilemma of steppe and it's transformation in China. Chinese Science Bulletin, 61(2): 165-177. (in Chinese)

Zhang Z H, Duan J C, Wang S P, et al. 2012. Effects of land use and management on ecosystem respiration in alpine meadow on the Tibetan plateau. Soil and Tillage Research, 124: 161-169. 